\title{
The dynamics of economic action and the problems of its social embedding - Ethical challenges in view of the nascent commercial use of outer space
}

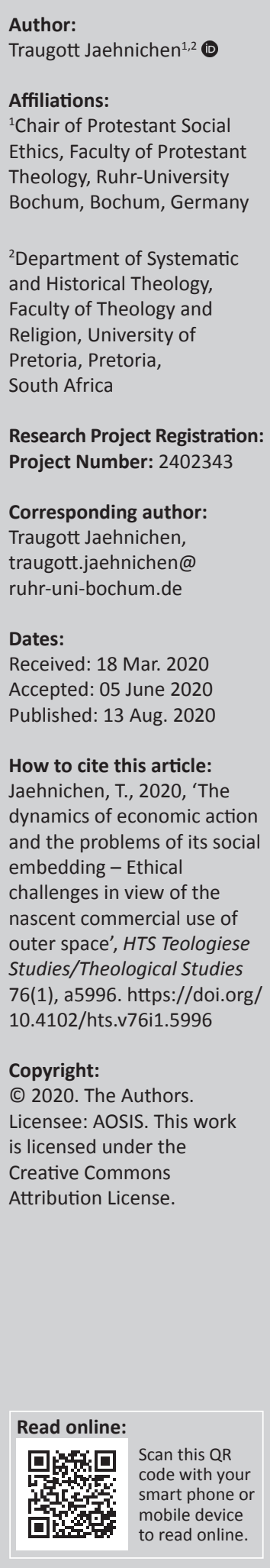

As a result of the increasing economical exploitation of outer space, humanity faces a new challenge that, as well as having economic advantages, also entails a great many ecological hazards. At present, the human race is encroaching on outer space, particularly in the form of almost 5000 active satellites and the corresponding space debris they produce. For the large part, this debris burns up on entering the Earth's atmosphere, yet time and again it still does cause damage. However, this could change dramatically if, as is now foreseeable, further uses of outer space, such as tourism, so-called satellite mega-constellations, regular transport flights to the moon or even Mars and the extraction of water and valuable rocks from celestial bodies, are expanded. There is a danger that ecological damage like that of the earlier phases of economic development will become externalised and ultimately pose a threat to the whole of humanity. Sautter's 'global "sustainability trilemma"' remains unresolved. This trilemma consists in the fact that, in political resolutions, 'the growth of resource-intensive prosperity is weighted far more highly than the conservation of functioning ecosystems and the implementation of inter- and intragenerational "justice"' and that there are "up until now no efficient and ethically acceptable solutions' for this problem. In this situation, it is therefore more important that rules for the sustainable use of outer space be established and enshrined as legally binding so that it becomes possible to minimise or even to preclude negative ecological consequences.

Contribution: Although the commercial use of outer space does not seem to be a crucial point, it marks a new step of the dynamics of modern economics that has to be identified as an important ethical challenge. The article discusses aspects of ethics, law, religion and economy in a multidisciplinary way.

Keywords: Sustainable exploitation of outer space; Earth charter; Astro-ecology; Industrialisation of creation; Luxembourg Space Agency (LSA); Space X (Space Exploration Technologies Corporation); Satellite debris; UNOOSA.

\section{Introduction}

\section{The unboundedness of modern industrial exploitation logic}

It is one of the fundamental qualities of humanity to transcend boundaries. Paths to the unknown have been tried and tested again and again and, ultimately, successfully practised. By the end of the 19th century, there was hardly a patch left on Earth that was still 'terra incognita' and, since the 1950s, humankind has been on its way to space. For some time after the conquest of the moon and the stationing of a scientific station in space, these developments have been in stagnation. At present, though, new radical, far-reaching developments seem to be emerging, not least because strong private economic actors are planning to and starting to use space commercially. Economic activity is the sub-area of human activities in which an almost limitless dynamic has been apparent since modern times.

According to the concise diagnosis by the theologian and classical exponent of cultural Protestantism Ernst Troeltsch (1922):

$[O]$ nly one word is needed to characterise modern economic development, capitalism; namely capitalism is not merely an industrial and financial business, but a form of capitalist business in general that affects craftsmanship and agriculture in the same way. (p. 308)

By striving for an optimal utilisation of invested capital, the 'capitalist form of business' has a tendency towards limitless, universal expansion. In this way, not only are all areas of economic 
action determined by this calculation, as already expressed by Troeltsch, but gradually the entire realm of experience. This has been making itself felt since the end of the 20th century at the latest, when, following on the health sciences and social sciences, finally art has also come to be determined based on the optimum utilisation of the invested capital. Finally, the spatial extension of the 'capitalist operational form of business' also tends to be boundless, as Marx and Engels (1980) already observed in the Communist Manifesto:

[T] he need of a constantly expanding market for its products [with the addition, of course, of the use of raw materials and increasingly, in an age of globalization, of a worldwide network of production sites] chases the bourgeoisie over the entire surface of the globe. It must nestle everywhere, settle everywhere, establish connections everywhere. (p. 49)

This dynamic of optimum utilisation, tending towards limitless growth and increasing acceleration, leads to the enforcement of a (Troeltsch 1922):

$[M]$ ore rigorous rationalisation of the entire way of life by the consistent application of the 'rational-scientific method' of technology, ... the rational art of division of labour, the predictability of each value at certain exchange values and ultimately the construction of the whole existence of economic laws. (p. 309)

This economic dynamism has proved to be immensely successful and has led to an increasingly optimal and historically unprecedented adequate supply of goods and services to people. At the same time, the unboundedness logic inherent in this dynamic has triggered high negative costs, namely costs that are not considered in the area of the economy itself but that nevertheless have a negative impact on people's lives. On the one hand, the social cultures of many societies are undermined by this logic, and on the other hand, to a very considerable extent their natural livelihoods have been claimed and, in part, destroyed. Because the dynamism of economic action in the 'smooth functioning of an endless process' (Arendt 1981:123) threatens to be absolute, the critical discourses in capitalism since the nineteenth century have repeatedly raised the question of the extent to which this logic of unboundedness can be balanced by forms of social and sustainable embedding (cf. Granovetter 1985; Polanyi 1977). In this sense, most industrialised nations have gradually developed systems of social security since the end of the 19th and the first third of the 20th century, and some elements of ecological regulation of economic activity since the end of the 20th century. See for example the tenth article of the Earth Charter (ECI 2000), stating:

$[E]$ nsure that economic activities and institutions at all levels promote human development in an equitable and sustainable manner.

This article (ECI 2000) also lists the following points:

1. Promote the equitable distribution of wealth within nations and among nations.

2. Enhance the intellectual, financial, technical, and social resources of developing nations, and relieve them of onerous international debt.
3. Ensure that all trade supports sustainable resource use, environmental protection, and progressive labour standards.

4. Require multinational corporations and international financial organizations to act transparently in the public good, and hold them accountable for the consequences of their activities.

At the level of many nation states and within the framework of international agreements, the concept of sustainability ${ }^{1}$ has been advanced and has become a regulatory model that has attempted a reasonable integration of economic, social and environmental concerns. Sustainability is also an essential concept for the future viability of societies, as it considers not only the interests of present-day people but also those of future generations, for example, the Brundtland Report (cf. World Commission on Environment and Development [WCED] 1987). Even though these attempts at embedding economic action have remained inadequate in many respects, the perspective of sustainable embedding and thus the regulation of economic action have been opened. In the process, it is important not only that sustainability be proclaimed as a social objective but also that it be 'translated' into the language of economics, and particularly that prices be structured accordingly to include ecological costs (cf. Luhmann 1986).

In particular, the Sustainable Development Goals (SDGs), put forth by the United Nations (UN), are an expression of the efforts to significantly improve the social, economic and ecological situation on Earth by 2030. In the current situation of the nascent commercial exploration of outer space, capitalist economic dynamics are developing beyond the sphere of the globe, and a qualitatively new step towards unbounded economic activity is emerging.

\section{Current activities for the economic exploitation of outer space: The Luxembourg Space Agency and the Space Exploration Technologies Corporation}

At present, the activities of the private business sector in this regard are to be seen in three areas in particular:

1. developing improved transport capacities for satellites, supply flights to the International Space Station (ISS) and - given the potential installation of further space stations, especially in the moon's orbit or on the moon itself - with the goal of facilitating flights to Mars by means of an intermediate stopover

2. the development of space tourism and

3. the search for and exploration of resources in outer space.

A state-based institution that is a typical example of the last of these categories is the Luxembourg Space Agency (LSA),

1.Progress and development are not necessarily synonyms. On the way to 2030 , there are critical voices towards the notion of 'sustainability' as well. 
which aims to establish new forms of property rights by, amongst other things, exploiting and subsequently marketing water and minerals from the moon within the next 10 years and from asteroids and even Mars within the next 15 years. (cf. Luxembourg Space Agency 2018). This represents a new stage in the use of outer space. Whereas until now individual nation states were primarily active in space, with an agenda originally based on prestige, research and satellite-based communication strategies, there is currently increasing commercial interest amongst both state-sector and private-sector actors. In this respect, various state actors are interested in forms of coordinated use, for example, of mineral raw materials from the area of space. Besides the interim objective of utilising asteroids for the extraction of raw materials, the main interest in the future is likely to be in a corresponding exploration of the moon. ${ }^{2}$ The moon is a vast storehouse of raw materials (aluminium, iron, magnesium, the gaseous energy provider helium-3, water ice from which hydrogen and oxygen can be extracted, etc.), and it also offers further raw materials resulting from asteroid impacts. Up until now, the extraction of these resources has been frustrated by the complexity of searching for them, mining them and, especially, transporting them to Earth. If and when such an utilisation of the moon should become possible, this raises a whole series of legally and ethically pertinent questions. To whom do the resources on the moon belong? Only to those who extract them or, potentially, to humanity as a whole? If the perspective of the common good should come to prevail, corresponding to the concept of the social and ecological embedding of capitalist economic activity, this immediately raises the question as to possible political actors. Could the UN be that actor? This whole question becomes concrete regarding the levying and application of possible taxes arising from the economic utilisation of resources from outer space. Would such taxes be incurred only in the country that organises the extraction of the raw materials and/or in which their transport lands, or is there an ethically founded claim on the part of humanity as a whole, so that these taxes could be used, in particular, for the achievement of SDGs?

These questions are more urgent, given that huge advances have been made, especially over the past 10 years, in overcoming the technological transportation challenges, so that these will in all probability be manageable in the foreseeable future. At present, the Space Exploration Technologies Corporation (Space X) is proving particularly successful; this company was initially largely financed by Elon Musk and was originally founded with the long-term objective of facilitating human life on other planets, at first on the moon and later Mars. Primarily on its own initiative, but partly with the support of the National Aeronautics and Space Administration (NASA), Space X has advanced to the position of a corporate global leader in the area of space travel with regard to the development and testing of the corresponding carrier rockets (the Falcon model range) and transport capsules (Dragon systems). It is a major supplier to the International Space Station and, in 2017, ousted Arianespace as the global market leader for satellite starts. Currently, Space X started with stationing the first satellites intended for mega-constellations in orbits at an altitude of between $1150 \mathrm{~km}$ and $1275 \mathrm{~km}$. According to Musk's plans, as many as 44000 satellites $^{3}$ are to be stationed in outer space in the next few years in order to provide stable high-speed Internet access around the globe. These roughly desk-sized elements orbit around the Earth closer than the satellites that are already in space. They therefore reflect the light of the sun brightly enough to be visible to the naked eye. This leads to an extreme increase in light pollution as a new aspect of space pollution. The constellations, which for millennia were important landmarks for humanity, will hardly be recognisable anymore. At present, it is only astronomers who have recognised the disruptive effect of the existing and constantly rising number of satellites on their observation activities and who are beginning to raise the alarm. There is hardly any discussion at all of the cultural consequences of the profound changes to the visibility of the stars in the firmament, the possible impact of this new form of light pollution on people's health and the question as to further ecological consequences with regard to the significant foreseeable increase in satellite debris (cf. Welt am Sonntag, 8 March 2020:49).

A special feature of the technological breakthrough is that Space $X$ enables the first stage of the Falcon carrier rocket to re-land on the Earth, thereby allowing it to be recycled. Currently, Space $X$ is also working on means by which to recycle the payload fairing and the second stage. A further, even more important, development is the option whereby the Dragon transport capsule can successfully land in an ocean, thus allowing it too to be recycled. This feature makes the Dragon capsule the only cargo system that is currently able to transport larger payloads back to Earth from outer space (at present, that is, from the ISS), whereas other cargo systems in use at present burn up on their return journey as they re-enter the Earth's atmosphere.

A further Space $X$ objective is the development of space tourism. Space $X$ plans to convey tourists to the ISS and, in the mid-term, to the moon at extremely high costs of an estimated $\$ 500,000$ (to the ISS including accommodation) or up to $\$ 1.5$ million to the moon. Flights to the weightlessness of zero gravity, to the edge of outer space or suborbital flights will be considerably less expensive, and they will very soon be possible and available as part of the tourism programme. Especially in this area, Blue Origin and Virgin Galactic are two of Space X's competitors.

3.This might increase the probability of Kessler's proposition with regard to space pollution. 


\section{Farther-reaching plans for the economic exploitation of outer space: Blue Origin and Virgin Galactic}

Jeff Bezos founded his own space company, Blue Origin, with the company motto gradatim ferociter [step by step, but determined], which best describes his activities. Richard Branson is the founder of the company Virgin Galactic, which in December 2018 successfully flew the unmanned SpaceShipTwo (SS2) more than $80 \mathrm{~km}$ into space, landing it safely again back on Earth. The $80 \mathrm{~km}$ zone is where NASA recognises the boundary to outer space, which is why passengers crossing that boundary are entitled to call themselves 'astronauts'.

Bezos and Branson are currently engaged in a race against each other to be the first to offer safe and regular flights for tourists into space. Branson may possibly have secured himself an advantage in that race. His aim is to make outer space potentially accessible to all people, just as, for example, the Caribbean is today. One of Bezos' projects aims in the same direction. The first step of Bezos' Blue Origin seems to be the development of a kind of space tourism by offering reusable rockets in capsules with large windows for tourists, who can experience a few minutes of weightlessness and a view of the Earth from outside in a border area to space (approximately $80 \mathrm{~km}$ high). The potential economic revenue to be gained from space tourism is very high. Analysts of the Swiss bank UBS anticipate that, in 10 years' time, the sales volume could amount to three billion dollars per year (cf. Beutelsbacher 2019:38). If, in addition to this, further technological innovations make rockets more affordable and the ticket prices drop accordingly (current estimates are that the price of a flight to the edge of outer space will be $\$ 75000$, and a suborbital flight $\$ 250$ 000), this could result in the development of a new, high-price segment form of luxury tourism, as opposed to what at present is still no more than an amusement for very rich eccentrics.

The next step in Bezos' development will be, similar to what Space $X$ is already doing, the development of payload transport rockets to transport people and material into space on a larger scale than before. Bezos' (2018:29) vision is to 'see millions of people working and living in space'. At its core, the Blue Moon project envisaged by Bezos is aimed at a transport service to the moon in order to be able to supply it, in the sense of a delivery service - as in the sense of a form of 'space Amazon'. This is of course thought of as a precondition for a possible colonisation of the moon. In addition, Bezos indicated in an interview his vision to dispose of highly contaminated waste from the Earth on the moon in order to solve various problems of disposal of highly toxic substances on Earth, an extremely problematic way of acting. Bezos does not allow any insight into the level of his economic investments; it is assumed that he has invested approximately one billion dollars in these projects. Branson would appear to be investing comparable sums, and in the meantime Google and others have come on board as shareholders in Space X.

\section{The need to 'embed' economic activities in outer space politically and legally}

These extremely ambitious projects of private companies in space obviously mark a new qualitative leap in economic history. In addition to the advanced technical and possibly humane visions, however, as with all economic projects, possible negative external effects must be taken into account. And so, it is worth briefly outlining the current commercial exploitation of space here in light of the possible environmental consequences of the far-reaching and massive economic investment-related initiatives of these private enterprises that are seeking to implement economically profitable space projects.

All these activities - raw material extraction, tourism, transport and in particular the waste management industry - are heavily burdened with ecological problems on Earth. This problem is also likely to become apparent in space. Emissions of $\mathrm{CO}_{2}$ from regularly run outer space shuttles would thus entail problematic ecological consequences, like those of ocean-cruise and long-distance flight tourism on Earth. These might well even be new risks, because very little research has yet been done on the potential effects on the low Earth orbit. A carbon tax should be levied as compensation for the $\mathrm{CO}_{2}$ emissions of the planned space tourism and the outlined transport activities - as is done on the corresponding negative effects of tourism and the transport industry on Earth - the income from which must only be used for measures to promote sustainability. As regards this objective, too, which is currently being widely discussed in many European Union countries (cf. Sautter 2017:393-398), it is imperative in view of the projected developments of space tourism that transnational solutions, ideally a global solution, be sought, with the UN as the key political actor.

Apart from this, space debris from disused satellites and so on also already poses a serious ecological problem on its re-entry into the Earth's atmosphere. It is ultimately unclear whether and how the frequently discussed permanent storage of toxic, or perhaps even nuclear, waste end products on the moon, as is planned in Bezos' projects, might entail problematic ecological consequences. Safety standards would have to be extremely high to ensure that, in the event of space accidents, highly toxic wastes cannot be released into the Earth's or the moon's atmosphere. Moreover, the disposal of waste on the moon can only be at best a provisional solution, because this could conflict with the declared objectives of a space-station settlement on the moon or the extraction of resources from the moon. Even though the immediate effects of such actions will have a 
much longer time frame than comparable effects on the Earth, it is crucial, especially at the present stage, to take precautions against placing a problematic ecological strain on outer space.

Nevertheless, in view of these activities, the demand for a redefinition of the concept of sustainability, which also includes space, is irrefutable. As humanity gradually begins to exploit space both technically and economically after the conquest of the Earth, the question arises on a new level as to how this economic dynamic can be embedded socially and culturally and, in particular, regulated by law (cf. Hobe 2019), at least in principle, by an order created by democratically legitimised actors. At present, there are virtually no valid international 'rules of the game' for private sector actors in this area, except for technological restrictions and the more or less large economic resources. Because technological progress in this area is also extremely dynamic and, in addition to pioneering entrepreneurs, other economic players, such as financial investors with investments in Blue Origin, Space X or Virgin Galactic, are gradually starting to enter this business of the future, it is necessary to draw up a framework at this point in time in order to include social and above all ecological concerns in the further development of a 'space economy', in addition to economic interests. The existing provisions of national states for economic activities in outer space which, moreover, are at present only regulated in very few countries - primarily protect private property rights. In addition, initiatives are being developed that are geared towards reliable international regulations for investors. In view of the high investment efforts involved, this is highly justified. However, sustainability is an objective that plays either a subordinate role or hardly any role at all. Even though sustainability is explicitly mentioned as a goal in some instances, such as in Luxemburg (cf. Luxembourg Space Agency 2018), this is done without any concrete strategies or specifications regarding the matter being named.

The most important actor for such a project is - as already repeatedly implied - the United Nations, especially the United Nations Office for Outer Space Affairs (UNOOSA), which throughout the years has considered different aspects of the long-term sustainability of outer space activities. Unfortunately, the Agreement Governing the Activities of States on the Moon and Other Celestial Bodies, also known as the Moon Treaty, created in 1979, that tries to turn jurisdiction of all celestial bodies (including the orbits around such bodies), has not been ratified by any state engaged in outer space activities and therefore has no relevancy in international law. Building on previous efforts, in 2010 the Scientific and Technical Subcommittee began considering as an agenda item the long-term sustainability of outer space and established a working group with a view to proposing measures that could enhance sustainability and producing voluntary guidelines to reduce risks to longterm sustainability.
In June 2018, with UNISPACE + 50, the Millennium Space Conference of the United Nations, the UN strengthened their efforts to add space sustainability to the sustainability discussion. In September 2018, the UNOOSA and the UN Office for Partnerships and Space Trust combined forces to host 'Space2030 agenda: Space as a driver for peace', an event that involved broad representation ranging from private and public sponsors within the space community to heads of state and top government officials. Together, they discussed the importance of cooperating at an international level on the peaceful use of space as well as on the role space might have as a peace driver. The event also represented an ideal occasion for considering the impact space is having on the implementation of the 2030 Sustainable Development Agenda. The road towards attaining this goal will be mapped by the Space2030 agenda, which is to be negotiated by UN member states over the next 2 years within the UN Committee on the Peaceful Uses of Outer Space (COPUOS). This implies a fundamental shift in the understanding of and attitude towards space within the UN system, as it involves member states in outlining how space science and technology might be utilised towards achieving the goals of the 2030 Sustainable Development Agenda.

Yet more is needed. Despite the difficulties of decision-making and the lack of democratic legitimacy of the UN and its suborganisations, the UN should create a new institution analogous to the World Trade Organization in order to develop framework conditions for economic activities in space. The time window for the creation of such a framework, however, seems to be limited. So far, only major investments have been made in this area, and various projects have been launched, but commercial use in the true sense of the word has not yet begun. In this respect, harsh conflicts of interest are possible, for example between individual states, profitoriented players or the United Nations, as regards the question of who can assert which property rights to minerals or other resources from asteroids or even from the moon, for example. These will be unavoidable once commercial use begins, but they are currently less pronounced, so that there are certainly opportunities for regulation in this area to be justified based on contract theory. It will be important to make the successes and deficits in the attempts to implement the concept of sustainability on Earth fruitful for this new area of economic activity. Human action in general, and in particular economic action on the horizon of capitalist exploration logic, tends to be based on boundless dynamics and expansion.

\section{Conclusion}

This fascinating side of human action, which characterises modern times in a special way, can be described in Karl Polanyi's words as a 'great transformation' (Polanyi 1973). Polanyi has made it clear in his universal historical studies that, in accordance with this unbounded logic of modern economy, new forms of embedding economic action must be developed repeatedly. Poised as it is on the frontier of such unbounded development, humanity seems to be set 
to embark on the commercial exploration of space, so the issue of sustainability in space must be given a prominent place on the international community's political agenda. At least the most serious negative external costs caused by the first 'great transformation' on Earth since the beginning of the 19th century should be avoided in space in the interest of all of humanity, because possible negative consequences as regards the disturbance of the Earth's atmosphere or the pollution of the moon with highly toxic and possibly even nuclear waste must be taken into account as serious threats. It would be much better to advance a convincing concept of space sustainability at the present time and in parallel with the evolving commercial use of space.

In light of this, it is imperative that binding rules for the use of outer space be developed at an organised international level in the context of the United Nations and for them to be monitored by the UNOOSA. At the same time, a system of possible sanctions would have to be devised for the event of any infringement of these rules and enforced by an agent with powers to act. The experience of history since the forced industrialisation of the 19th and 20th centuries shows that powerful actors are required to embed the tendentially unbounded logic of economic exploitation. Should humanity fail in this task without succeeding in organising a sustainable use of outer space, the implications would be at least as dramatic as the foreseeable impact of climate change in consequence of the excessive use of fossil energy sources. About the present threshold situation, the opportunity exists of choosing to follow a path that leads to sustainable development in respect of the exploration uses made of outer space. What is proposed here are rules for the utilisation of space, not the abuse (exploitation) of space.

\section{Acknowledgements}

The author thanks Prof. J. Buitendag, Faculty of Theology and Religion, University of Pretoria.

\section{Competing interests}

The author declares that he has no financial or personal relationships that may have inappropriately influenced him in writing this research article.

\section{Author's contributions}

T.J. is the sole author of this research article.

\section{Ethical considerations}

This article followed all ethical standards for research without direct contact with human or animal subjects.

\section{Funding information}

This research received no specific grant from any funding agency in the public, commercial or not-profit sector.

\section{Data availability statement}

Data sharing is not applicable to this article as no new data were created or analysed in this study.

\section{Disclaimer}

The views and opinions expressed in this article are those of the author and do not necessarily reflect the official policy or position of any affiliated agency of the author.

\section{References}

'Axel Springer Award 2018', Welt am Sonntag, 28-29 April, 2018, pp. 28-30.

Arendt, H., 1981, Vita Activa, W. Kohlhammer GmbH, Munich.

Beutelsbacher, S., 2019, 'Zurück zum Mond', Welt am Sonntag, 14 July, 2019, p. 38

Earth Charter International (ECI), 2000, Social and economic justice, viewed 15 April 2020, from https://earthcharter.org/read-the-earth-charter/social-and-economicjustice/.

Granovetter, M., 1985, 'Economic action and social structure: The problem of embeddedness', American Journal of Sociology 91(3), 481-510.

Hobe, S., 2019, Space law, Nomos-Verlag, Baden-Baden.

Luhmann, N., 1986, Ökologische Kommunikation. Kann die moderne Gesellschaft sich auf ökologische Gefährdungen einstellen?, Westdeutscher Verlag, Opladen.

Luxembourg Space Agency, 2018, 'Study summary of the space resources value chain study', pp. 3-19, Luxembourg Space Agency, Luxembourg.

Marx, K. \& Engels, F., 1980, Manifest der Kommunistischen Partei, Dietz Verlag, Berlin Polanyi, K., 1973, 'The great transformation', Politische und ökonomische Ursprünge von Gesellschaften und Wirtschaftssystemen, Suhrkamp Verlag, Frankfurt.

Polanyi, K., 1977, The livelihood of man, Academic Press, New York, NY.

Sautter, H., 2017, Verantwortlich Wirtschaften: Die Ethik gesamtwirtschaftlicher Regelwerke und des unternehmerischen Handelns, Metropolis Verlag, Marburg.

Troeltsch, E., 1922, 'Das Wesen des modernen Geistes', in Gesammelte Schriften, pp. 308-325, Mohr/Siebeck, Tübingen.

World Commission on Environment and Development, 1987, 'Our common future', Brundtland Report, Oxford University Press, Greven. 